\title{
Research on Building Industry Competitiveness in 21 Prefectures of Guangdong Province
}

\author{
Aimin Wei \\ Email:524496523@qq.com, \\ 510925, Guangzhou, Guangdong province, \\ Guangzhou City Construction College
}

\begin{abstract}
The building industry output value accounts for $7 \%$ of the GDP in Guangdong province, but the problem of imbalanced development exists; the competitiveness in the 21 prefectures is uneven. Based on the statistical data of each city in Guangdong province from the year of 2005 to 2013, applying DEA model, resolving comprehensive production efficiency into technical efficiency and scale efficiency, the paper found the comprehensive production efficiency of Shenzhen, Guangzhou, Meizhou and Zhongshan is relatively higher, and Shanwei and Jiangmen is relatively lower; the disparity of efficiency value reaches to about 0.7 . Therefore, the paper suggested that government should formulate comprehensive development planning, strengthen the supporting force and optimize structure to further develop and strengthen the construction enterprises in Guangdong; innovate system, apply high technology, adopt di versified operating strategy, reasonably integrate resources, and accelerate the transformation from labor-intensive extensive operation to intensive operation; standardize issues management of administrative examination and approval, and improve service quality and efficiency.
\end{abstract}

Keyword- building industry; efficiency; competitiveness; analysis

\section{INTRODUCTION}

Building industry is one of the main industry to increase the fixed assets of the whole society in national economy, and it plays an important role in economic development in Guangdong province. In recent years, the building industry in Guangdong province achieved fast development, and the gross output value of building industry enterprises increased from 220.058 billion yuan in the year of 2005 to 792.713 billion yuan in 2013 . From the point of quantity, the building industry has made great development in our province. This paper used data envelopment analysis (DEA) method to evaluate the efficiency of building industry in our province from 2005 to 2013, analyzed the efficiency changes and its reasons, and provided reference and suggestions to improve the efficiency of building industry in our province.

TABLE I. THE MAIN INDEX OF BUILDING INDUSTRY IN GUANGDONG PROVINCE FROM 2005 TO 2013

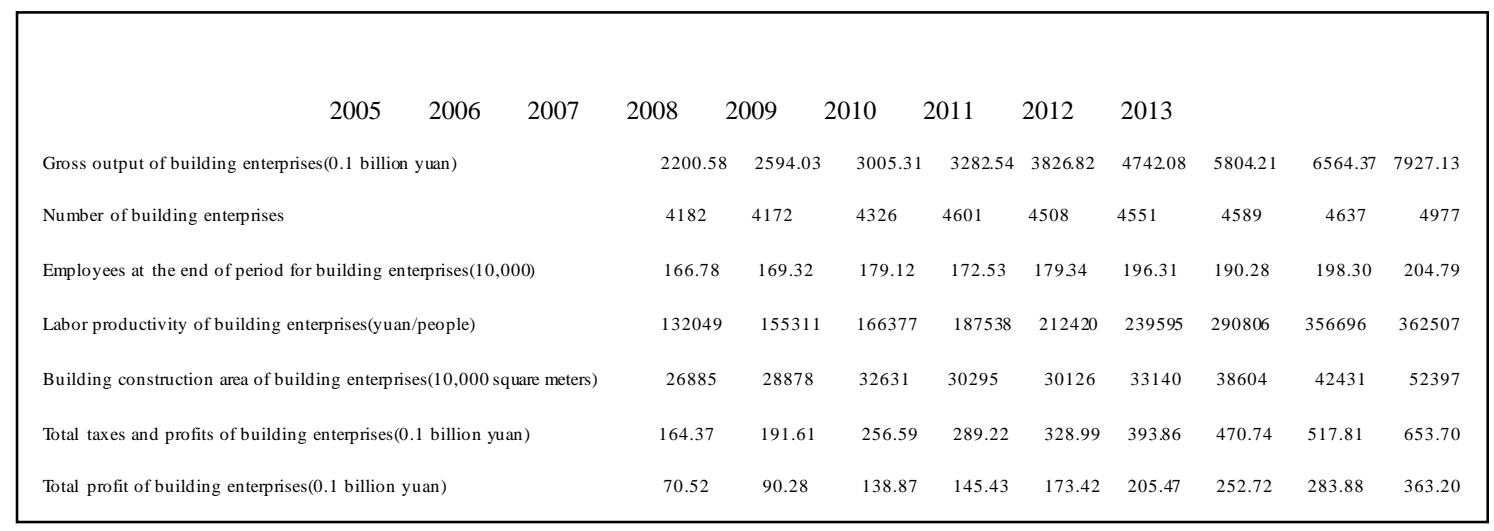

\section{LITERATURE REVIEW}

Scholars at home and abroad have extensively studied the production efficiency of building industry,
Wang Yousong and Zhang Yan(2000) evaluated and analyzed the production technical efficiency of our building industry during 1981-1996 through the establishment of one nonparametric econometric analysis model[2]; Lin Chen, Wang Yousong and Zhang 
Yan(2003) calculated and analyzed the production efficiency of building industry in Guangdong province during 1985-2000 by using DEA, which provided help to understand the input-output relationship and production efficiency of building industry in the 16 years in Guangdong province[3]; based on the cross-section statistical data of input-output of building industry of 31 provinces, cities and autonomous regions in mainland in 2002, Wang Yousong, Zhang Yan, Li Shaosong, Zhan Peng, and Xu Bingjin(2006) respectively set the econometric analysis models of nonparametric concave efficiency boundary and convex efficiency boundary, and calculated the efficiency value of production technology everywhere[4]; Ruan Lianfa, Zeng Hui, and Zhang Hui(2008) made empirical research on the eight premium quality building enterprises in Zhejiang province through Fuzzy Analytic Hierarchy Process(FAHP), and the research results showed its own competitive advantages and disadvantages of the eight super-fine class project general contractors[5]; Liu Xiaoyan and Wang Xueqing(2008) made effective DEA evaluation on the 31 provinces and areas from 2002 to 2006, determined the provincial order of competitiveness, analyzed the input superabundance and output ullage, found the main factors that lead to low competitiveness, and looked for ways to improve the competitiveness of provincial building industry[6]; Wang Yousong, Zhu Zhiyong, Tan Fangyu, and Zhang Yan(2008) analyzed and discussed the industry structure and competitiveness of building industry in Guangdong province with the research period from 2003 to 2007 by using shift-share analysis model, and put forward some suggestions to improve the building industry development and competitiveness ability in Guangdong province[7]; Liu Lei, Shi Xian, Zheng Shiqiao, and Du Xiuhong(2011) analyzed the operating efficiency of our building enterprises by using DEA model and Malmquist productivity index[8]; Zhang Xinli and Wang Yongliang made empirical analys is on the competitiveness of 22 target enterprises, and provided reference for improving comprehensive competitiveness of building enterprises by using evaluation index system and evaluation model[9]; Wang Jialing adopted the way of combining qualitative analys is with quantitative analys is to study China's building industry and its production efficiency [10]; by analyzing the building industry in Guangdong and other parts in China, Zhu Daojun found the development model of build ing industry is high input and high output, and suggested that the mechanization development road should be taken by enhancing the technology assembly rate level so as to achieve the goal of intensive development[11]; Ning Debao and Li Ying evaluated the efficiency of building industry during 2005-2010 by using DEA method[12]; Wang Xu, Li Lin and Deng Hongxing made comprehensive evaluation to the building industry competitiveness in China from two aspects of static evaluation and efficiency evaluation by using PP-DEA model, and divided into five grades through cons tructing competitivenes s index[13].

The above scholars studied the production efficiency of building industry all over the country from different angles, which to some extent reflected the production efficiency status of building industry around the country, and provided theoretical basis to improve the production efficiency in building industry. Based on the reference of existing research results, the paper chose the building industry of each city in Guangdong province as the objects of study, adopted DEA model, resolved comprehensive production efficiency into technology efficiency and scale efficiency, and studied the production efficiency of building industry in each city in Guangdong province from the two aspects of technology and scale.

\section{CALCULATION MODEL}

The calculation of building industry competitiveness in each city adopted the non-parametric econometric method, namely Data Envelopment Analysis(DEA), which does not have to establish function equation to determine the corresponding parameters, but forms the efficiency boundary containing all the data points by using its own structural features of input-output data set; the boundary is linearly composed of data points with relatively best efficiency(comprehensive efficiency value is equal to 1), and corresponding efficiency ratio of other points can be calculated through linear comparis on with the boundary. Obviously, the value range of $E R$ is $0 \leqslant E R \leqslant 1$. Because the analysis is based on the selected data set, the calculated value is the relatively comprehensive efficiency value within the scope of the data structure itself.

Suppose that the number of input is $m$, number of output is $\mathrm{k}$, and there are totally $\mathrm{n}$ sets of data. Name $\mathrm{X}$ as the input data matrix $(\mathrm{m} \mathrm{X} \mathrm{n})$, and $\mathrm{Y}$ as the output data matrix $(\mathrm{k} \mathrm{X} \mathrm{n}) ; \mathrm{X}$ and $\mathrm{Y}$ are the input matrix and output matrix of data points respectively that is to seek efficiency, and its ER can be obtained by solving following linear programming problems:

$$
\theta^{*}=\min _{\theta, \lambda} \theta
$$

(1-1)

$$
\begin{array}{ll}
\substack{\text { Objective function: } \\
\lambda Y \geq Y} & \hat{X}-\lambda X \geq 0 \\
& \begin{array}{l}
\lambda \geq 0 \\
\end{array}
\end{array}
$$

Cons traint condition:

Among them: $\lambda$ is variable line matrix with $n$ dimensions; single variable $\theta$ is the required ER. Because of the limitation of basic data source, the selected input and output variables are: $\mathrm{m}=2$ and $\mathrm{k}=2$.

It is generally believed that comprehensive (technology) efficiency is the multiply of pure technical efficiency and scale efficiency. Integrated (technology) efficiency is comprehensive measuring and evaluation to the resources allocation abilities and resources use efficiency of decision making units. Pure technical efficiency is the production efficiency affected by factors such as management and technology, which reflects the production efficiency of DMU with certain input factors; scale efficiency is the production efficiency affected by enterprises scale, which reflects the gap between actual scale and optimal production 
scale. When comprehensive (technical)efficiency is 1 , it shows the input and output of the decision-making unit is comprehensively effective, namely it is effective both in technology and scale at the same time. When pure technical efficiency is 1 , it shows the use of input resources is efficient at the current technical level; the root cause of failing to achieve comprehensive effectiveness is the invalid scale, therefore, the reform should focus on how to better play the scale efficiency.

\section{FUNDAMENT AL DAT A AND CALCULATION} RESULTS

According to the statistical data in <statistic yearbook of Guangdong province>, the statistic data of building industry in 21 cities in our province from 2005 to 2013 , the definitions are as follows:

Input value: take the gross output of building enterprises in 21 cities of our province from 2005 to 2013;
Input value: take the total profit of building enterprises in 21 cities of our province from 2005 to 2013;

Output value: take the floor space of building under construction of building enterprises in 21 cities of our province from 2005 to 2013 ;

Output value: take the employees at the end of period of building enterprises in 21 cit ies of our province from 2005 to 2013.

Analyze and process the raw data by adopting the DEAP2.1 software, which can get the trend of comprehensive (technical)efficiency, pure technical efficiency and scale efficiency of building industry in 21 cities of our province from 2005 to 2013 . The trend of the fundamental data of input and output, and mean value of comprehensive (technical)efficiency, pure technical efficiency and scale efficiency calculated by applying DEA mathematical model is shown in TABLE 1; comprehensive (technical)efficiency, pure technical efficiency and scale efficiency are listed in TABLE 2.

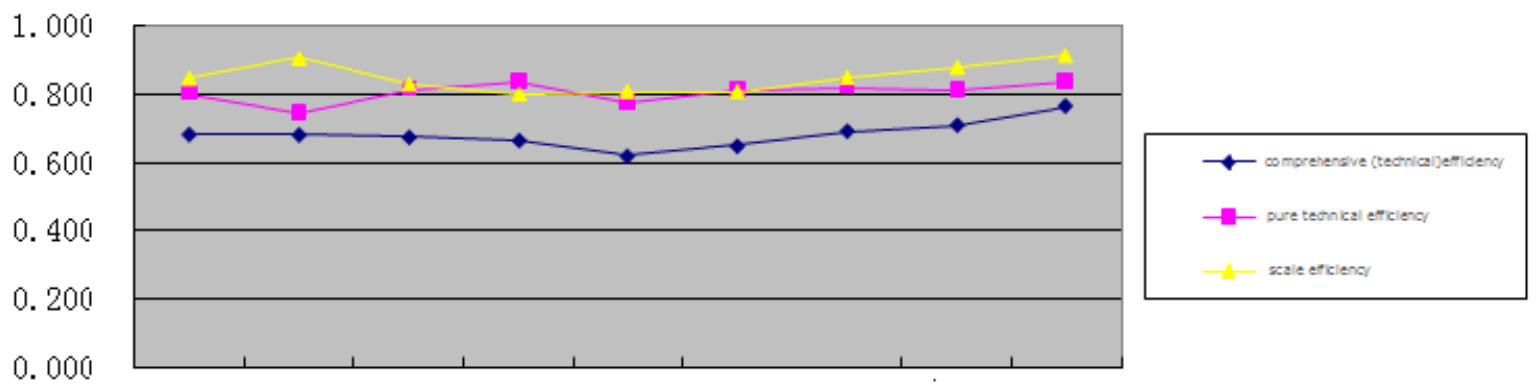

Figure 1. building industry efficiency value of each city in Guan gdong province from 2005 to 2013

According to the Fig .1, the trend of the mean value of comprehensive (technical)efficiency, pure technical efficiency and scale efficiency of building industry in 21 cities of our province is basically the same. Due to the economic crisis in 2008 and 2009, the trend dropped. In
2008, the scale efficiency value dropped to the lowest point of 0.799 in eight years; in 2009, comprehensive (technical)efficiency value and pure technical efficiency value respectively dropped to the lowest point of 0.619 and 0.775 in eight years.

TABLE II. COMPREHENSIVE EFFICIENCY, PURE TECHNICAL EFFICIENCY AND SCALE EFFICIENCY FROM 2005 TO 2013

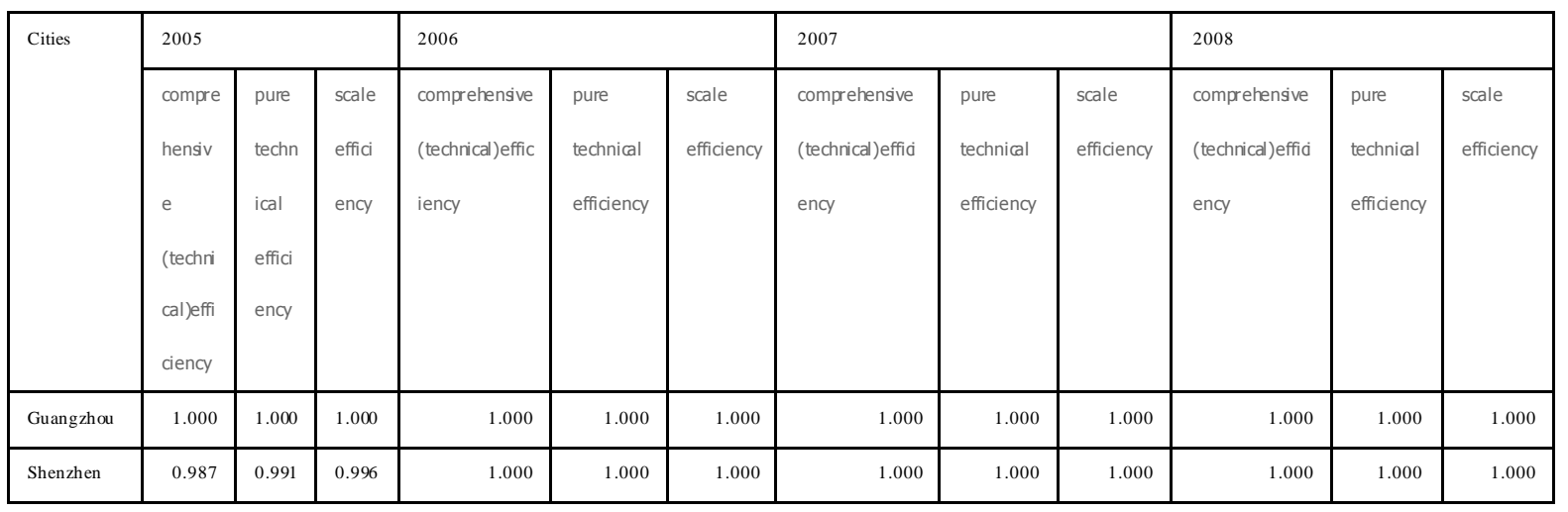




\begin{tabular}{|c|c|c|c|c|c|c|c|c|c|c|c|c|}
\hline Zhuhai & 0.987 & 1.000 & 0.987 & 0.843 & 0.968 & 0.871 & 0.827 & 0.995 & 0.832 & 0.883 & 1.000 & 0.883 \\
\hline Shantou & 0.492 & 0.544 & 0.904 & 0.501 & 0.522 & 0.960 & 0.522 & 0.558 & 0.935 & 0.512 & 0.560 & 0.915 \\
\hline Foshan & 0.764 & 0.772 & 0.989 & 1.000 & 1.000 & 1.000 & 1.000 & 1.000 & 1.000 & 1.000 & 1.000 & 1.000 \\
\hline Shaoguan & 0.577 & 0.693 & 0.833 & 0.445 & 0.466 & 0.955 & 0.439 & 0.555 & 0.792 & 0.471 & 0.625 & 0.753 \\
\hline Heyuan & 0.484 & 0.820 & 0.591 & 0.541 & 0.699 & 0.774 & 0.671 & 1.000 & 0.671 & 0.573 & 1.000 & 0.573 \\
\hline Meizhou & 1.000 & 1.000 & 1.000 & 1.000 & 1.000 & 1.000 & 1.000 & 1.000 & 1.000 & 1.000 & 1.000 & 1.000 \\
\hline Huizhou & 0.579 & 0.762 & 0.760 & 0.531 & 0.658 & 0.808 & 0.604 & 0.747 & 0.809 & 0.577 & 0.797 & 0.724 \\
\hline Shanwei & 0.507 & 1.000 & 0.507 & 1.000 & 1.000 & 1.000 & 0.630 & 1.000 & 0.630 & 0.328 & 1.000 & 0.328 \\
\hline Dongguan & 0.784 & 0.788 & 0.995 & 0.606 & 0.623 & 0.972 & 0.623 & 0.689 & 0.904 & 0.674 & 0.767 & 0.879 \\
\hline Zhongshan & 1.000 & 1.000 & 1.000 & 0.990 & 1.000 & 0.990 & 0.833 & 0.983 & 0.848 & 0.927 & 1.000 & 0.927 \\
\hline Jiangmen & 0.296 & 0.338 & 0.877 & 0.327 & 0.346 & 0.945 & 0.360 & 0.428 & 0.840 & 0.432 & 0.519 & 0.832 \\
\hline Yangjiang & 0.609 & 0.699 & 0.872 & 0.690 & 0.706 & 0.978 & 0.686 & 0.794 & 0.865 & 0.614 & 0.712 & 0.862 \\
\hline Zhanjiang & 0.469 & 0.559 & 0.839 & 0.482 & 0.545 & 0.884 & 0.601 & 0.667 & 0.902 & 0.533 & 0.606 & 0.880 \\
\hline Maoming & 0.553 & 0.583 & 0.948 & 0.552 & 0.576 & 0.959 & 0.530 & 0.573 & 0.926 & 0.424 & 0.503 & 0.843 \\
\hline Zhaoqing & 0.631 & 0.761 & 0.829 & 0.535 & 0.625 & 0.856 & 0.602 & 0.722 & 0.834 & 0.597 & 0.773 & 0.771 \\
\hline Qingyuan & 0.399 & 0.752 & 0.530 & 0.419 & 0.604 & 0.693 & 0.518 & 0.689 & 0.752 & 0.553 & 0.785 & 0.704 \\
\hline Chaozhou & 0.770 & 1.000 & 0.770 & 0.480 & 0.675 & 0.711 & 0.433 & 0.777 & 0.558 & 0.486 & 0.898 & 0.541 \\
\hline Jieyang & 0.881 & 1.000 & 0.881 & 0.749 & 0.779 & 0.962 & 0.701 & 0.916 & 0.765 & 0.900 & 1.000 & 0.900 \\
\hline Yunfu & 0.533 & 0.781 & 0.682 & 0.589 & 0.816 & 0.721 & 0.548 & 1.000 & 0.548 & 0.465 & 1.000 & 0.465 \\
\hline Mean value & 0.681 & 0.802 & 0.847 & 0.680 & 0.743 & 0.907 & 0.673 & 0.814 & 0.829 & 0.664 & 0.836 & 0.799 \\
\hline
\end{tabular}

TABLE III. COMPREHENSIVE EFFICIENCY, PURE TECHNICAL EFFICIENCY AND SCALE EFFICIENCY FROM 2005 TO 2013 (CONTINUED)

\begin{tabular}{|c|c|c|c|c|c|c|c|c|c|c|c|c|c|c|c|}
\hline \multirow[t]{2}{*}{ Cities } & \multicolumn{3}{|l|}{2009} & \multicolumn{3}{|l|}{2010} & \multicolumn{3}{|l|}{2011} & \multicolumn{3}{|l|}{2012} & \multicolumn{3}{|l|}{2013} \\
\hline & $\begin{array}{l}\text { comprehe } \\
\text { nsive } \\
\text { (technical } \\
\text { )efficienc } \\
\text { y }\end{array}$ & $\begin{array}{l}\text { pure } \\
\text { technica } \\
\text { I } \\
\text { efficienc } \\
\text { y }\end{array}$ & $\begin{array}{l}\text { scale } \\
\text { efficie } \\
\text { ncy }\end{array}$ & $\begin{array}{l}\text { compr } \\
\text { ehensi } \\
\text { ve } \\
\text { (techn } \\
\text { ical)ef } \\
\text { ficienc } \\
\text { y }\end{array}$ & $\begin{array}{l}\text { pure } \\
\text { technic } \\
\text { al } \\
\text { efficien } \\
\text { cy }\end{array}$ & $\begin{array}{l}\text { scale } \\
\text { efficien } \\
\text { cy }\end{array}$ & $\begin{array}{l}\text { compre } \\
\text { hensive } \\
\text { (techni } \\
\text { cal)effi } \\
\text { ciency }\end{array}$ & $\begin{array}{l}\text { pure } \\
\text { technic } \\
\text { al } \\
\text { efficie } \\
\text { ncy }\end{array}$ & $\begin{array}{l}\text { scale } \\
\text { efficie } \\
\text { ncy }\end{array}$ & $\begin{array}{l}\text { compreh } \\
\text { ensive } \\
\text { (technica } \\
\text { I)effidien } \\
\text { cy }\end{array}$ & $\begin{array}{l}\text { pure } \\
\text { techni } \\
\text { cal } \\
\text { efficie } \\
\text { ncy }\end{array}$ & $\begin{array}{l}\text { scale } \\
\text { efficie } \\
\text { ncy }\end{array}$ & $\begin{array}{l}\text { comp } \\
\text { rehen } \\
\text { sive } \\
\text { (tech } \\
\text { nical) } \\
\text { effici } \\
\text { ency }\end{array}$ & $\begin{array}{l}\text { pure } \\
\text { techn } \\
\text { ical } \\
\text { effici } \\
\text { ency }\end{array}$ & $\begin{array}{l}\text { scale } \\
\text { efficie } \\
\text { ncy }\end{array}$ \\
\hline Guangzhou & 0.932 & 1.000 & 0.932 & 1.000 & 1.000 & 1.000 & 1.000 & 1.000 & 1.000 & 0.967 & 1.000 & 0.967 & 0.911 & 1.000 & 0.911 \\
\hline Shenzhen & 1.000 & 1.000 & 1.000 & 1.000 & 1.000 & 1.000 & 1.000 & 1.000 & 1.000 & 1.000 & 1.000 & 1.000 & 0.979 & 1.000 & 0.979 \\
\hline Zhuhai & 0.725 & 0.846 & 0.858 & 0.707 & 0.853 & 0.829 & 1.000 & 1.000 & 1.000 & 1.000 & 1.000 & 1.000 & 1.000 & 1.000 & 1.000 \\
\hline Shantou & 0.492 & 0.513 & 0.959 & 0.470 & 0.513 & 0.917 & 0.465 & 0.486 & 0.956 & 0.489 & 0.492 & 0.994 & 0.674 & 0.693 & 0.974 \\
\hline Foshan & 0.787 & 0.813 & 0.968 & 1.000 & 1.000 & 1.000 & 0.857 & 0.868 & 0.988 & 0.615 & 0.653 & 0.942 & 0.627 & 0.637 & 0.985 \\
\hline Shaoguan & 0.448 & 0.551 & 0.814 & 0.560 & 0.695 & 0.807 & 0.553 & 0.659 & 0.839 & 0.745 & 0.761 & 0.979 & 0.961 & 0.968 & 0.992 \\
\hline Heyuan & 0.417 & 0.815 & 0.511 & 0.420 & 0.903 & 0.465 & 0.470 & 0.871 & 0.539 & 0.748 & 1.000 & 0.748 & 0.556 & 0.741 & 0.750 \\
\hline Meizhou & 0.999 & 1.000 & 0.999 & 0.609 & 0.634 & 0.960 & 1.000 & 1.000 & 1.000 & 1.000 & 1.000 & 1.000 & 0.583 & 0.586 & 0.996 \\
\hline Huizhou & 0.535 & 0.725 & 0.738 & 0.659 & 0.858 & 0.769 & 0.700 & 0.765 & 0.915 & 0.526 & 0.615 & 0.856 & 0.620 & 0.620 & 1.000 \\
\hline Shanwei & 0.393 & 1.000 & 0.393 & 0.370 & 1.000 & 0.370 & 0.380 & 1.000 & 0.380 & 0.419 & 1.000 & 0.419 & 1.000 & 1.000 & 1.000 \\
\hline
\end{tabular}




\begin{tabular}{|c|c|c|c|c|c|c|c|c|c|c|c|c|c|c|c|}
\hline Dongguan & 0.708 & 0.761 & 0.929 & 0.751 & 0.827 & 0.908 & 0.703 & 0.837 & 0.841 & 0.938 & 0.960 & 0.976 & 1.000 & 1.000 & 1.000 \\
\hline Zhongshan & 1.000 & 1.000 & 1.000 & 1.000 & 1.000 & 1.000 & 1.000 & 1.000 & 1.000 & 1.000 & 1.000 & 1.000 & 1.000 & 1.000 & 1.000 \\
\hline Jiangmen & 0.432 & 0.486 & 0.890 & 0.429 & 0.504 & 0.851 & 0.413 & 0.454 & 0.910 & 0.535 & 0.547 & 0.977 & 0.701 & 0.724 & 0.968 \\
\hline Yangjiang & 0.385 & 0.486 & 0.792 & 0.424 & 0.543 & 0.782 & 0.415 & 0.528 & 0.785 & 0.483 & 0.540 & 0.895 & 0.616 & 0.659 & 0.935 \\
\hline Zhanjiang & 0.475 & 0.533 & 0.891 & 0.500 & 0.559 & 0.894 & 0.546 & 0.546 & 1.000 & 0.477 & 0.506 & 0.941 & 1.000 & 1.000 & 1.000 \\
\hline Maoming & 0.432 & 0.497 & 0.868 & 0.498 & 0.572 & 0.871 & 0.577 & 0.603 & 0.956 & 0.689 & 0.716 & 0.963 & 0.561 & 0.565 & 0.994 \\
\hline Zhaoqing & 0.603 & 0.763 & 0.791 & 0.739 & 0.903 & 0.818 & 0.868 & 0.953 & 0.911 & 0.706 & 0.771 & 0.916 & 0.821 & 0.882 & 0.999 \\
\hline Qingyuan & 0.519 & 0.737 & 0.705 & 0.606 & 0.825 & 0.734 & 0.563 & 0.711 & 0.792 & 0.565 & 0.723 & 0.781 & 0.738 & 0.942 & 0.783 \\
\hline Chaozhou & 0.551 & 1.000 & 0.551 & 0.544 & 1.000 & 0.544 & 0.619 & 0.977 & 0.634 & 0.461 & 0.824 & 0.559 & 0.373 & 0.930 & 0.401 \\
\hline Jieyang & 0.704 & 0.824 & 0.854 & 0.850 & 0.893 & 0.952 & 0.915 & 0.995 & 0.919 & 0.851 & 0.916 & 0.930 & 0.734 & 0.989 & 0.742 \\
\hline Yunfu & 0.458 & 0.926 & 0.495 & 0.473 & 1.000 & 0.473 & 0.477 & 0.964 & 0.495 & 0.645 & 1.000 & 0.645 & 0.564 & 0.707 & 0.797 \\
\hline Mean value & 0.619 & 0.775 & 0.807 & 0.648 & 0.813 & 0.807 & 0.691 & 0.820 & 0.850 & 0.708 & 0.811 & 0.880 & 0.763 & 0.837 & 0.915 \\
\hline
\end{tabular}

According to the TABLE 2, the cities of comprehensive (technical)efficiency, pure technical efficiency and scale efficiency of building industry in 21 cities of our province in 2005 that all reach to the relative efficiency are Guangzhou, Meizhou and Zhongshan.
The cities that have optimal comprehensive (technical)efficiency, pure technical efficiency and scale efficiency and the cities that have worst comprehensive (technical)efficiency in 21 cities of our province from 2005 to 2013 are shown in TABLE 3.

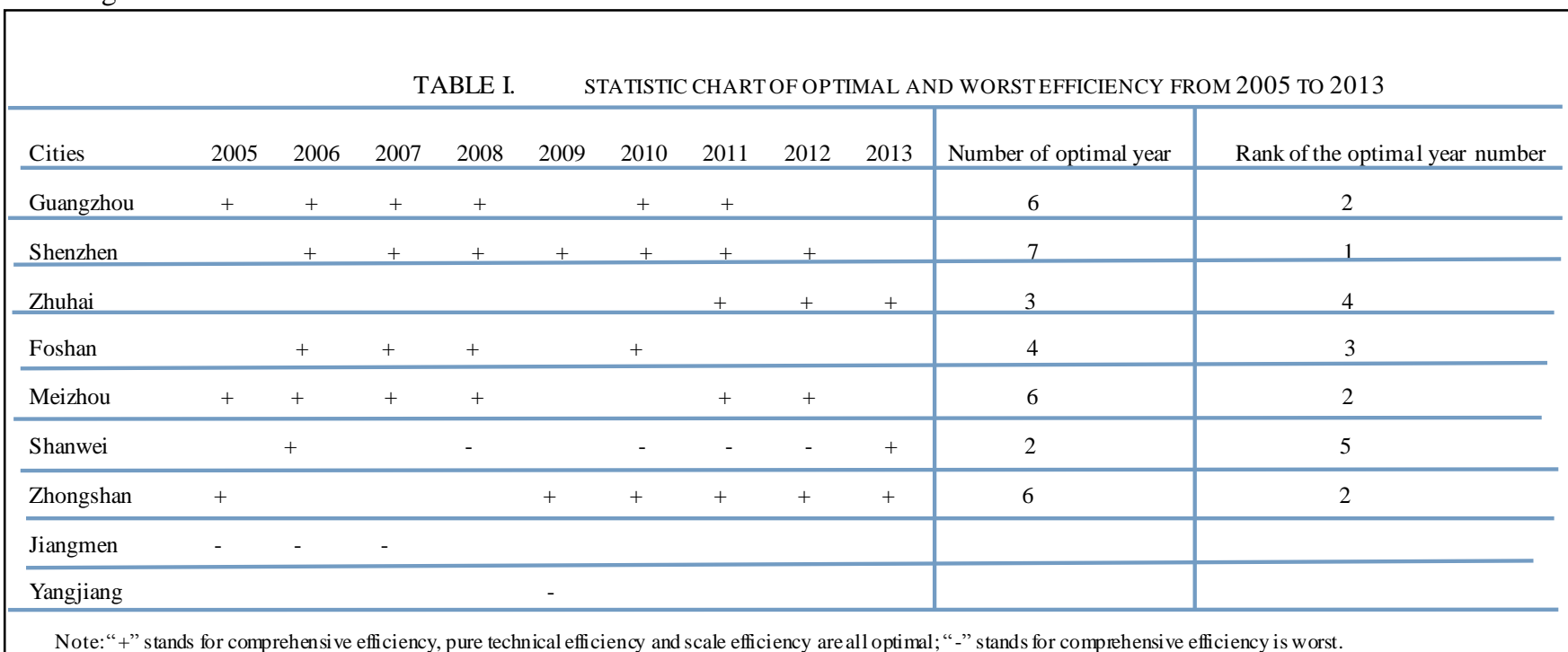

According to the TABLE 3, from 2005 to 2013, the city with optimal comprehensive (technical)efficiency, pure technical efficiency and scale efficiency in most years was Shenzhen; Guangzhou, Meizhou and Zhongshan were in the second place; Foshan was in the third place. From 2005 to 2013, Shanwei had the worst comprehensive (technical)efficiency in four years; Jiangmen had the worst comprehensive (technical)efficiency in three years; Yangjiang and Chaozhou had the worst comprehensive (technical)efficiency in one year.

\section{COMPETITIVENESS EVALUATION}

According to the above data and analysis, it can be concluded that the mean value of comprehensive (technical)efficiency, pure technical efficiency and scale efficiency in 21 cities of our province is not high; the cities with relatively optimal comprehensive (technical)efficiency, pure technical efficiency and scale
Guangdong province, so it's badly in need to speed up the development of building industry of each city in Guangdong province and improve the overall competitiveness. (1) the government should formulate comprehensive development planning, increase the intensity of support, optimize the structure, further develop and strengthen the building enterprises in Guangdong. On account of the problems such as small-scale building scale, not strong strength, unreasonable structure and poor regulation, the enterprise structural adjustment should be intensified; the large-scale enterprises should be vigorously supported, and the vitality of enterprises in building field should be constantly enhanced; the construction of credit system and information platform should speed up to maintain the good order of building market. (2) innovation system and the application of high technology. Adopt diversified business strategy, reasonably integrate resources, and speed up the transformation from labor-intensive extensive 
management to intensive management. To change the current extensive management way of high input, high consumption, high growth and low efficiency, it has to save energy, reduce consumption, reduce enterprise cost, earn greater profits and promote the rapid development of enterprises; to adapt to the new situation and new changes, it is needed to speed up the operational mechanism transformation, transform management idea, strengthen enterprise internal management, and finally realize the transformation from production enterprise to management enterprise. (3) standardize management of administrative examination and approval items, and improve service quality and efficiency. According to the principle of "lean, efficient, prag matic and convenience", continue to implement "window one-stop" services, uniformly accept and standardize the receipt, clear within time limit, consciously accept supervision from the electronic monitoring system, achieve work standardization and refinement, and practically increase work efficiency.

\section{ABOUT THE AUTHOR}

Wei Aimin, female, born in 1977, Cantonese, lecturer, build ing economy research as the main research direction. Wei Aimin Email address: 524496523@qq.com Phone number: 13925119162

Postal code: 510925 Address: Department of Architectural Engineering, Guangzhou City Construction College, 166 Huanshi East Road, Conghua, Guangzhou,

\section{REFERENCES}

[1] Bureau of Statistics in Guangdong province. Statistic yearbook in Guangdong province[M]. Beijing: China Statistics Press, 2005-2012.
[2] Wang Yousong, Zhang Yan. Evaluation and analysis on the production technology efficiency in building industry [J]. Journal of South China University of Technology(natural science edition), 2000(10).

[3] Lin Chen, Wang Yousong, Zhang Yan. Evaluation and analysis on the production technology efficiency in building industry in Guangdong province [J]. Journal of South China University of Technology (natural science edition), 2003(1).

[4] Wang Yousong, Zhang Yan, Li Shaosong, Zhan Peng, Xu Bingjin. Comparative study on production technology efficiency in building industry $[\mathrm{J}]$. <Journal of Guangdong University of Technology>, 2006(1)

[5] Ruan Lianfa, Zeng Hui, Zhang Hui. Construction and empirical analysis on competitiveness evaluation system of building enterprises [J].Building economy, 2008(4).

[6] Liu Xiaoyan, Wang Xueqing. Study on competitiveness of building industry in China based on DEA [J]. Building economy, 2008(11).

[7] Wang Yousong, Zhu Zhiyong, Tan Fangyu, Zhang Yan. Analysis on industrial structure and compet it iveness of building industry in Guangdong province [J].Construction management modernization, 2009(1).

[8] Liu Lei, Shi Xian, Zheng Shiqiao, Du Xiuhong. Evaluation on dynamic efficiency of our building enterprises [J]. Building economy, 2011(11).

[9] Zhang Xinli, Wang Yongliang. Comprehensive evaluation on competitiveness of building enterprises [J]. Building economy, 2011(12).

[10] Wang Jialing. Analysis and countermeasure study on production efficiency calculation of our building industry [D]. Chongqing: Chongqing University, 2011.

[11] Zhu Daojun. Analysis on production efficiency of building industry in Guangdong province based on DEA model [D]. Guangzhou: South China University of Technology, 2011.

[12] Ning Debao, Li Ying. Study on efficiency evaluation of our building industry based on DEA method [J]. Building economy, 2012(7).

[13] Wang Xu, Li Lin, Deng Hongxing. Comprehensive evaluation study on the competitiveness of our building industry based on PP_DEA model [J]. Technology economy and management research, 2013(8). 